\title{
45
}

\section{A SYNCHRONOUS COLLABORATION SERVER FOR THE CONSTRUCTION INDUSTRY - \\ THE END USERS' EXPERIENCE IN THE COLLABORATOR PROJECT}

\author{
Anfosso Alain \\ CSTB, FRANCE, alain.anfosso@cstb.fr \\ Bourdeau Marc \\ CSTB, FRANCE, marc.bourdeau@cstb.fr \\ Zarli Alain \\ CSTB, FRANCE, alain.zarli@cstb.fr \\ Costicoglou Socrates \\ SPACE HELLAS S.A, GREECE, scostic@space.gr \\ Poggi Agostino \\ CNIT, ITALY,poggi@ce.unipr.it
}

\begin{abstract}
The COLLABORATOR project has developed a synchronous collaborative web-based system dedicated to mobile workers and virtual teams for the construction industry. This paper describes the work related to the specification, development and assessment of the aforementioned solution, emphasising the impact on the working practices. Discussing the technological aspects of the COLLABORATOR solution in comparison with existing systems, this paper describes the methodology followed to capture end-user requirements and specify the prototype services. The added value of the solution has been assessed against two operational scenarios, giving the opportunity to consider new emerging practices in the day-to-day work life while taking into account the deployment constraints.
\end{abstract}

\section{INTRODUCTION}

For a good progress and efficiency, a construction project requires frequent meetings between actors. Most of them are planned in advance or periodically, whilst others may occur without being anticipated when unexpected problems arise or urgent decisions have to be taken. In any case, all meetings require the presence of attendees. Now ensuring the physical presence of all attendees is the point where difficulties can arise when considering the number of actors involved in a 
construction project and the high level of mobility of some of them. Besides the numerous small enterprises involved, workers who have a management position or an expertise function take part in several projects at the same time. De facto situation entails many journeys for this category of workers, keeping them out of their office most of the time: we call them "mobile workers" all along this paper.

Today ICT-based collaboration between construction actors mainly takes place using asynchronous services: e-mailing with document attached, document sharing via a centralised project web server, etc.. However, first signs of advanced synchronous collaboration tools between distant participants appear, that provide new opportunities compared to the already used mobile voice communication.

What is the real added value of synchronous collaboration services for mobile workers? Through the experience provided by the EC-funded COLLABORATOR project (IST programme), this paper presents end users requirements for mobility in the construction sector, the scenarios defined and evaluated for the construction domain, and the main results of the project.

\section{INNOVATIVE ASPECTS OF COLLABORATOR}

\subsection{ICT supported collaboration: state of the art}

Extensive research work on ICT-supported collaboration and/or mobility has been undertaken these last years. Examples of significant trans-sectorial projects on collaboration frameworks are CVW (an open source project on collaborative virtual workspaces, http://cvw.sourceforge.net) or PEPITO (peer-to-peer implementation and theory, http://www.sics.se/pepito). Projects like UNITE (ubiquitous and integrated teamwork environment, http://www.unite-project.org/public/index.html), CAROUSEL (collaboration framework for ubiquitous accessing to Community Grid systems, http://grids.ucs.indiana.edu/ptliupages/projects/carousel/index.htm) or MOBIlearn (context-sensitive approach to informal, problem-based and workplace learning, http://www.mobilearn.org) introduce mobility together with collaboration issues. Besides, some other projects focus on specific collaboration topics such as generic frameworks (ANTS, http://ants.etse.urv.es), flexible environments for distance learning (CHEF, http://www.chefproject.org/index.htm), or collaboration model (GARNET, http://www.cs.indiana.edu/ ohsangy/papers/pdagarnet_final.pdf).

In the construction sector, mobility and collaboration have been addressed in projects like MEMO (interactive multimedia services to mobile and portable terminals using DAB technology), MICC (data and voice services over wired and wireless networks using DECT and ISDN technologies), COSMOS (mobility support relying on HYPERLAN and satellite networks, http://www.ipsi.fraunhofer.de/mobile/projects/cosmos), and SABARECO (remote multi-project reporting and controlling by using satellite based infrastructure, http://www.sabareco.com).

As well, many solutions are currently available on the market, providing collaborative features like conferencing, collaborative meeting, and resource sharing through the Internet. Examples are WebEx, Centra, PlaceWare and Latitude initiatives. 
It is a common practice to position collaboration systems in a three-dimensional space identified by the dimensions "communication", "co-operation" and "coordination" (see figure 1 below).

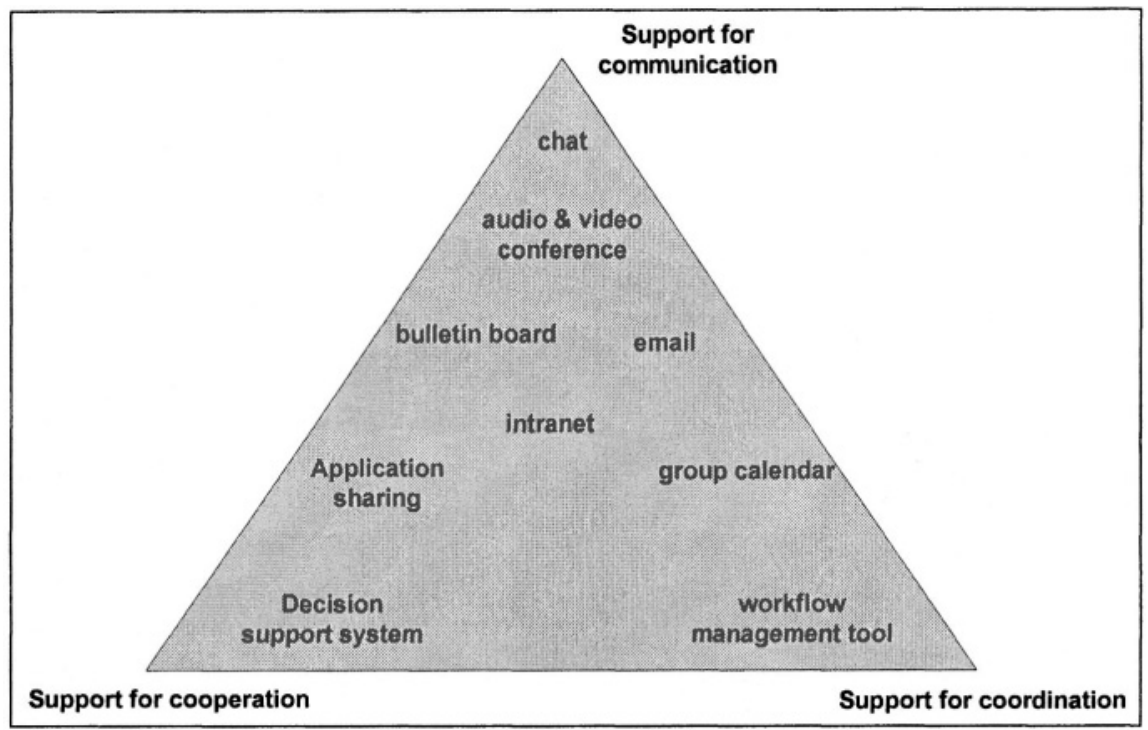

Figure 1: Dimensions of collaboration support

A major differentiator for collaboration support systems is the focus either on synchronous collaboration or on asynchronous collaboration. Typical features for supporting synchronous collaboration are application sharing, audio and video communication, a whiteboard or the shared editing of documents. Typical features that support asynchronous collaboration are a messaging component, a shared calendar and a document repository.

Until recently most collaboration support systems were located on either one or the other of these two sides. Microsoft NetMeeting, a popular solution for point-topoint audio and video conferencing, for example, is firmly on the side of synchronous collaboration. It provides audio and video communication, a whiteboard and the shared editing of documents but does not provide, for example, a document repository. BSCW, on the other hand, which is a widely used groupware, is located firmly on the side of asynchronous collaboration support, providing messaging, calendaring and shared repositories but not conferencing.

\subsection{Innovative collaboration features of COLLABORATOR}

The COLLABORATOR ${ }^{1}$ project (COLLABOrative FRAmework for RemoTe and MObile UseRs, IST-2000-30045, 2001-2003) aims at providing individuals and

1 The COLLABORATOR consortium was composed of the following partners: SPACE HELLAS (Greece, project co-ordinator), CNIT-Consorzio Nazionale Interuniversitario per le Telecomunicazioni (Italy), TILAB-Telecom Italia LAB (Italy), ATOS Origin Integration (France), CSTB (France), TAUTechnologia Automazione Uomo (Italy), and UPM-Technical University of Madrid (Spain). 
project team members with a shared workspace that can be accessed by any device and network. It exploits seamless integration of standard Web technologies with agent technologies to support remote and collaborative work in virtual teams offering the following features:

- Platform-independence and Web integration: COLLABORATOR is based on the standard technologies of the Web (Java, HTML, TCP/IP, etc.) and it is operating system and network agnostic;

- Ubiquitous accessibility: COLLABORATOR can be used seamlessly on desktop computers and on handy devices with sufficient processing power and bandwidth;

- Collaboration transparency: COLLABORATOR supports off-the-shelf applications and make them available to virtual teams without any modifications;

- Multi-document sharing: COLLABORATOR is not limited to a single application and the virtual team is provided with a shared desktop capable of containing many applications concurrently.

Besides numerous features provided by "traditional" collaborative systems such as presentation facilities, co-browsing, audio, video conferencing, application sharing, remote control, file sharing, annotation features/white board, text chat feature, moderator controls, participant controls, session recording, event management and interface customisation, COLLABORATOR provides specific features that are of interest and need to be mentioned:

- Terminal personalization: the principle is to accommodate seamlessly wired and wireless terminals and to adapt the users' experiences to the capabilities of the terminal.

- User adaptation: thanks to such a feature, people involved in the virtual meeting are associated with personal agents mediating their agendas.

- Push information towards users: the purpose is to supply users with information as soon as it is available enhancing the basic portal technology available today with the integration of the push "information" paradigm.

- Ubiquitous access to the session: in order to support (supply) unanticipated sharing and late joining.

- Meeting moderation: by providing integrated floor control policies during a virtual meeting session.

- Easy add-on (integration) of current (off-the-shelf or built-in) applications (asynchronous, synchronous) and access from heterogeneous user devices.

While COLLABORATOR targets a generic solution for supporting collaborative work between virtual teams, two application domains have been selected for the purpose of specifying and testing the proposed solution on real life scenarios: the construction and the telecom domains.

\section{CAPTURE OF REQUIREMENTS}

The capture of requirements aims at establishing basis of functional, ergonomic and technological recommendations for the development of a collaborative server relying on the use of the Internet technologies, especially adapted to the construction sector and its mobile workers. This task has been cut out in 4 phases described in the next sections. 


\subsection{Identification of generic services eipected from a collaborative system}

The first step of the study aimed at eliciting basic activities, while the second step consisted in identifying services based on those activities, as reported in (Anfosso, 2002).

Basic activities identified along our study have been classified according to the asynchronous or synchronous characteristic of the collaborative exchange. Administrating users, sending a message, sharing a document, using and managing agendas are considered as asynchronous basic activities. Having a chat, having an audio/video conference, sharing a specific device (e.g. a white-board) or sharing an application are considered as synchronous basic activities.

Five main families of services consisting of a number of basic activities have been identified:

1) Group presentations are multicast, enabling passive viewing from offices or rooms. This increases awareness and interaction among geographically distributed participants, and allows remote viewers to interact with each other and the speaker. Group presentations make uses of real-time audio and video for both formal and informal interactions.

2) Group calendar enables information to be centrally posted by authorised users and accessed by the general public. Also, calendars can be used for private purposes requiring user $\log$ in. Users browse, filter and search for events or bookings that meet their needs. Changes, additions or cancellation of events cause email notification to all interested parties.

3) Discussion forum is a collaborative system where people from any location participate in discussions on any topic in specific areas of interest called forum or newsgroup. Users participate in a discussion forum by reading the messages (sometimes called articles) and responding to them.

4) Personal notes is a system where individuals can create, rank, and annotate personal notes created with e.g. their PDAs in order to make a decision upon a subject.

5) Virtual meeting is a collaborative environment providing a shared space where mobile end users, after becoming participants in a given "virtual" meeting, can communicate application-specific data to other participants in the same meeting until a goal is achieved. Within virtual meeting service, group calendar, and also asynchronous basic services (e.g. email) are of particular interest for the meeting organisation.

\subsection{End-user requirements and potential collaborative services for mobile workers in construction}

User requirements have been collected from available literature, past experiences, and results of research projects such as EC2 (Bourdeau, 2002). Partially founded by the French Ministry of Industry, the EC2 project has allowed to define tracks of services for mobile workers in construction, based on the analysis of their working practices and requirements for new organisational modes and new ways for communicating, accessing and sharing information in mobility situations: 
- Individual services: most of them are linked to the "virtual desktop" concept for the management of personal information: management of personal agenda and address book, access to e-mail service, recording of all kinds of information (texts, drawings, photos, ...) related to a construction project.

- Collective services: these services involve the community of actors participating to a construction project. They can be divided into synchronous collaborative work services and asynchronous collaborative work services.

\subsubsection{Synchronous collaborative services}

This consists in virtual meetings organised in addition (or substitution) to regular and contractual physical meetings, or for discussing and reaching a decision on particular and sensitive issues. These meetings should be supported by audio and video conferencing facilities, while allowing sharing of documents or applications.

\subsubsection{Asynchronous collaborative services}

These services are related to the creation of, access to, or sharing of information in an asynchronous way. For example, we can quote:

- Access to project documentation (plans, technical specifications, schedules, reports, etc.);

- Handing over of orders (between teams);

- Acceptance of work (recording of reservations);

- Handling of materials and products on site;

- Checking of sub-contracting companies personnel;

- Recording of work progress.

The EC2 study also emphasized some constraints specific to the deployment of such kind of services on construction sites, like robustness and adaptation to the work environment (quality of display, etc.).

\subsection{Collaborative scenarios for the construction domain}

Focusing on real-time (synchronous) collaborative work, many scenarios related to potential virtual meetings can be identified all along a construction project:

- Programming stage: virtual meeting between a project manager and a client.

- Design stage: virtual meeting between various stakeholders (architect, engineering teams, chartered-building surveyor...).

- Construction (erection) stage: virtual meeting during a regular site meeting between some project participants that are physically present (e.g. in the construction hut) and some other remote actors.

- Facility management stage (and possibly also during the previous stage): spontaneous virtual meeting between a decision requester (e.g. a maintenance operator) and a decision maker (e.g. an expert), for real-time decision.

Various topics may be addressed during these meetings: technical, administrative, juridical, financial or business topics, urban planning, architecture, environment and site constraints, scheduling, logistics (supply chain), etc. Despite the variety of meeting activities, it is possible to identify three main types of meetings:

- Study meeting: most of the time it takes place during the design phase for a new or a rehabilitation construction program. A study meeting can also be 
organised during the preparation phase of the site. It mainly deals with technical, financial and administrative topics.

- Site meeting: it is a periodic management and technical meeting dealing with project progress issues during the erection stage of the construction project.

- Work meeting: it is a periodic or non-periodic meeting aiming to investigate a specific topic (technical, financial, legal or administrative).

Each type of meeting can be characterised as regards its frequency, the various actors possibly involved with their roles during the meeting, and the topics addressed. As an example, table 1 presents the results for a site meeting.

Table 1: Characteristics of a site meeting

\begin{tabular}{|c|c|c|c|}
\hline Frequency & Involved actors & $\begin{array}{c}\text { Corresponding } \\
\text { roles } \\
\end{array}$ & $\begin{array}{l}\text { Main subjects in } \\
\text { case of presence }\end{array}$ \\
\hline $\begin{array}{l}\text { Periodic: } \\
\text { generally every } \\
\text { week, with a fixed } \\
\text { date }\end{array}$ & $\begin{array}{l}\text { Client } \\
\text { Client's } \\
\text { representative } \\
\text { Designer } \\
\text { Pilot } \\
\text { Building contractors } \\
\text { Guests }\end{array}$ & $\begin{array}{l}\text { Attendee } \\
\text { Chairman } \\
\text { Attendee } \\
\text { Attendee } \\
\text { Attendee } \\
\text { Attendee }\end{array}$ & $\begin{array}{l}\text { Technical } \\
\text { Technical } \\
\text { Technical } \\
\text { Technical } \\
\text { Technical } \\
\text { Technical }\end{array}$ \\
\hline
\end{tabular}

A particular sub-type of work meeting is the "remote decision meeting": it mainly occurs either during the construction (or rehabilitation) stage - in that case the "site manager" (acting as a decision requester) is involved with the architect (acting as a remote decision maker) - or in the maintenance stage - beside the user or the property owner, the owner representative, the caretaker, the managing agent and the maintenance contractor(s) are involved in the building maintenance (see table 2).

Table 2 : Remote decision classification

\begin{tabular}{|l|l|l|l|}
\hline \multicolumn{1}{|c|}{ Stage } & Frequency & \multicolumn{1}{c|}{ Actors } & \multicolumn{1}{c|}{ Corresponding roles } \\
\hline Erection & $\begin{array}{l}\text { At short } \\
\text { notice }\end{array}$ & $\begin{array}{l}\text { Client's representative } \\
\text { Building expert } \\
\text { Site representative } \\
\text { Client }\end{array}$ & $\begin{array}{l}\text { Decision maker or requester } \\
\text { Decision maker } \\
\text { Decision requester } \\
\text { Decision requester or maker }\end{array}$ \\
\hline $\begin{array}{l}\text { Facility } \\
\text { management }\end{array}$ & $\begin{array}{l}\text { At short } \\
\text { notice }\end{array}$ & $\begin{array}{l}\text { Maintenance expert } \\
\text { Maintenance agent } \\
\text { Managing agent } \\
\text { Facility manager (or } \\
\text { caretaker) } \\
\text { Building's user }\end{array}$ & $\begin{array}{l}\text { Decision maker } \\
\text { Decision requester } \\
\text { Decision requester } \\
\text { Decision requester }\end{array}$ \\
& & \multicolumn{2}{|l}{} \\
& & \multicolumn{2}{|l}{} \\
& & & \\
& &
\end{tabular}

From the above typology, two scenarios (the most representative ones) have been selected, implemented and validated. They gather the main concerns of mobile workers all along a construction project:

- Site meeting (mMeeting scenario): This scenario relates to a virtual meeting between a project team located in a construction site hut and a mobile worker (a "methods manager") who cannot physically attend. The chairman of the meeting, namely the architect, calls the meeting (a week before) by using the group calendar application where he edits the agenda and selects the 
necessary attendees. The invitation is automatically sent by the system to the attendees, who then confirm their participation. During the site meeting, the attendees in the site hut and the "mobile" attendee share a virtual white-board and a planning tool (MS Project), and communicate thanks to the video conferencing functionality provided by the multimedia application. If a second authorized mobile worker, using a PDA requests to attend the virtual meeting, he can also use audio conferencing, view and share the white-board and the planning tool. This scenario has been entirely played through a wireless network.

- Remote decision meeting (mDecision scenario): This scenario relates to a virtual meeting between an expert in his office and a maintenance operator somewhere in a building, equipped with e.g. a PDA connected to the COLLABORATOR server through a wireless network. When the maintenance operator requests a decision to fix a problem, he first needs to join a relevant expert. By using the group calendar and according to the profile of the searched expert, the system provides a list of possible experts. The expert selected by the maintenance operator is then requested either by email or phone call. When the expert connects to the COLLABORATOR server (by using his computer, for instance a WiFi laptop), he joins the session where the maintenance operator has requested a remote decision. Using a camera plugged on his PDA, the operator can show what he can see while discussing with the expert.

\subsection{Requirements for the COLLABORATOR system}

A common approach has been followed for the construction and telecom domains by identifying for each selected scenario how and when it is applied, what is the context, who are the actors of the scenario, what is the infrastructure at one's disposal and/or required, and the different actions performed user per user during the scenario. This is illustrated through the following text, extracted from the mMeeting scenario description. Corresponding requirements are referenced at the end of each elementary action, e.g. [RU1].

Before the meeting (time scale: days or hours)

1. "Collaborative system" (Group calendar) helps the chairman to:

Select a date and a venue for the coming meeting according to the availability of attendees and infrastructures [RS1, RS3, RS10, RI1-2]

- Invite the attendees and communicate the definitive date, venue and agenda of the meeting [RS2, RS4, RU1-4]

- Help to create or prepare the new meeting report [RR1, RS11]

2. "Collaborative system" helps the attendees to confirm or not theirpresence to the meeting [RN1-2]

3. "Collaborative system" helps the chairman to create a new collaborative session with the definition (selection) of the means required for the meeting, e.g., to use or not: chat, [RA4]

audio/video conferencing [RI6]

application sharing (along with the shared application) [RP1]

document sharing (along with the shared document) [RA3, RD1 -6]

Requirements have been classified by nine main categories (management functions): User management / Document management / Session management / Application (sharing) management / Presence management / Notification 
management / Infrastructure management / Audio-Video and Chat management / Report management.

An extract of the table of end-user requirements is given hereafter:

Table 3 : Extract of end-user requirements

\begin{tabular}{|c|l|l|c|}
\hline ID & User management & Coming & Helpful with \\
\hline$R U 1$ & Team definition & before & mMeeting, mDecision, $m$ Work \\
\hline$R U 2$ & User role definition in the project & before & mMeeting, $m$ Decision, $m$ Work \\
\hline$R U 3$ & Choose meeting attendees in a list & before & mMeeting, mDecision, $m$ Work \\
\hline$R U 4$ & Guest user & before & all scenarios \\
\hline ID & Document management & Coming & Helpful with \\
\hline$R D 1$ & Load and Save document & any time & all scenarios \\
\hline$R D 2$ & Document security Access & any time & all scenarios \\
\hline$R D 3$ & Session document & any time & all scenarios \\
\hline$R D 4$ & Team document & any time & all scenarios \\
\hline$R D 5$ & Remote document access & any time & all scenarios \\
\hline$R D 6$ & Document variety & any time & all scenarios \\
\hline
\end{tabular}

\section{EVALUATION OF THE COLLABORATOR PROTOTYPE}

\subsection{Prototype implementation}

The COLLABORATOR prototype has been implemented according to a 3-tiers architecture, based on three major communication components: application sharing, multimedia and agent processing. Both Java and Windows applications are supported.

Based on standard server-side technologies, COLLABORATOR exploits the Java 2 Enterprise Architecture and a number of related off-the-shelf technologies to implement a high-performance, robust, scalable infrastructure for supporting large collaborative sessions. It is built on top of a portal service infrastructure based on industry standard portal technologies, such as XML, Apache, Jetspeed, and EJB. More detailed information can be found in (Bergenti, 2002), (Pozzi, 2003) or (Bergenti, 2003).

\subsection{Prototype evaluation}

Both scenarios have been demonstrated to a panel of construction end users. They reacted quite positively and found real business interest in the system, even if at present time the full value of synchronous collaboration in mobile activities (especially for video communication and more precisely on a PDA) is not clearly perceived. This last point is probably due to the low performance of current PDAs.

Requested improvements are in the area of communication infrastructures: their deployment is a key issue to enlarge the access to the system and generalise the use of the service by mobile construction workers. Even if numerous experiences have been launched to deploy high rate networks in isolated regions, the network availability is not guaranteed in no man land sites and a satellite network connection

\footnotetext{
${ }^{2} \mathrm{mWork}$ is a scenario proposed for the telecom domain.
} 
is still too expensive for a standard construction project. In addition, there is also a problem of network availability in old or unwired buildings, in particular in the basement where most of machineries are located (lift, central heating...).

Another important parameter to be considered is the quality of service for videoconferencing on IP protocol. This is probably a shortage of IPv4, and we are eager to see how it will be implemented on IPv6 and deployed by network providers.

\section{CONCLUSION AND PERSPECTIVES}

Synchronous collaboration through Internet is now a reality even if the needed infrastructure is currently under deployment. Numerous communication solutions are at disposal and can be easily installed with some experience in network configuration. Indeed wired or wireless adapters (e.g. for Wifi, Bluetooth) and wired adapters (e.g. power line connectors) can be found off-the-shelf and do not require additional cabling work in a building.

New technologies such as micro controllers and wireless technologies have opened doors for entirely new types of computing devices. that make it possible to be connected to Internet from anywhere. In addition, highly specialized computing devices such as digital cameras, audio players, digital books etc. have also started to appear, blurring the distinction between computers and other electronic appliances.

From a technological perspective, the ongoing migration of computing and information access from the desktop to mobile computing devices poses critical challenges for human-computer interaction. These devices have limited screens and no keyboard or mouse, making complex graphical interfaces cumbersome. Furthermore, since mobile devices are used in situations involving different physical and social environments, tasks, and users, they need to allow users to interact using whatever mode or combination of modes are most appropriate given the situation and their preferences and abilities.

Exploiting the "always on" connectivity of next generation Internet and mobile infrastructures, the next step of ICT research for construction will have to investigate on R\&D paths to support ubiquitous and secure communication, process integration and context-aware services in collaboration, multi-modal interfaces and intuitive interactive modes (ROADCON).

\section{REFERENCES}

1. Anfosso A., Bourdeau M., Costicoglou S. "Future Collaborative Services for Mobile Workers in Construction". eSMART 2002 Conference: Towards a European Knowledge Economy, Salford University, UK, November 2002.

2. Bourdeau M. and alii. "Espace Coopératif Construction (EC2) - Rapport final". UCIP project n ${ }^{\circ} 01$ 290 6072, France, October 2002.

3. Bergenti F., Poggi A., Somacher M.. "A Collaborative Platform for Fixed and Mobile Networks". Communications of ACM, 45(11):39-44, November 2002.

4. Poggi A., Bergenti F., Somacher M., Costicoglou S. "COLLABORATOR: A collaborative system for heterogeneous networks and devices". ICEIS03 - International Conference on Enterprise System, Angers, France, April 2003.

5. Bergenti F., Costicoglou S., Poggi A. "A Portal for Ubiquitous Collaboration”. UMICS 2003 Ubiquitous Mobile Information and Collaboration Systems, Klagenfurt/Velden, Austria, June 2003.

6. Hannus M.and alii. "Construction ICT Roadmap". ROADCON (IST-2001-37278), September 2003. 